\title{
Effect of growth hormone therapy in children with achondroplasia: growth pattern, hypothalamic-pituitary function, and genotype
}

\author{
H Tanaka, T Kubo, T Yamate, T Ono, S Kanzaki and Y Seino \\ Department of Pediatrics, Okayama University Medical School, Okayama, Japan \\ (Correspondence should be addressed to H Tanaka, Department of Pediatrics, Okayama University Medical School, 2-5-1 Shikata-cho, \\ Okayama 700, Japan)
}

\begin{abstract}
Objective: Although there are a few reports on GH therapy in achondroplasia, these were based on a small sample and/or short-term observation. To clarify the effectiveness of GH treatment on short stature in achondroplasia and hypochondroplasia, a long-term treatment study in a larger number of patients was performed.

Method: Forty-two children (16 males and 26 females, age 3-14 years) with achondroplasia were examined in this study. Initially, we evaluated hypothalamic-pituitary function and point mutation analysis as previously reported. After the evaluation, the children were treated with $\mathrm{GH}$ for more than 2 years; then post-treatment growth velocity and body proportion parameters were determined. Results: The 35 typical variants of our achondroplasia patients showed previously reported point mutation in the fibroblast growth factor receptor 3 gene. The annual height gain during GH therapy was significantly greater than that before therapy $(3.9 \pm 1.0 \mathrm{~cm} /$ year before treatment vs $6.5 \pm 1.8 \mathrm{~cm} /$ year for the first year and $4.6 \pm 1.6 \mathrm{~cm} /$ year for the second year of treatment). The body disproportion had not been aggravated during the treatment period.

Conclusion: We conclude that GH might be beneficial in the treatment of short stature in children with achondroplasia in the first 2 years of treatment.
\end{abstract}

European Journal of Endocrinology 138 275-280

\section{Introduction}

Achondroplasia $(\mathrm{ACH})$ is the most common form of chondrodysplasia in humans. This disorder is inherited as an autosomal dominant trait, although the majority of cases are sporadic. Recent studies have revealed point mutations in the transmembrane domain of the fibroblast growth factor receptor 3 (FGFR3) gene in $\mathrm{ACH}$ heterozygotes and homozygotes $(1,2)$.

$\mathrm{ACH}$ is characterized by short-limbed dwarfism, macrocephaly with a prominent forehead, and midface hypoplasia. Adult height may be as short as $118-145 \mathrm{~cm}$ for men and 112-136 cm for women (3). Such extremely short stature and disproportion causes considerable inconvenience in daily life and places considerable psychological pressure on patients and their families. Although surgical lengthening of lower limbs has been the only established therapy for increasing overall height and improving body proportions, this procedure requires long-term hospitalization and may result in serious complications, such as post-operative infection and fractures or deviation of the bone axis (4).
Recently, there have been some reports describing the beneficial effects of growth hormone $(\mathrm{GH})$ therapy in $\mathrm{ACH}$ and hypochondroplasia $(\mathrm{HCH})(5-7)$, although patients with $\mathrm{ACH}$ are considered to have normal $\mathrm{GH}$ secretion. In fact, $\mathrm{GH}$ has been widely used to treat non-GH-deficient forms of short stature, such as Turner's syndrome, skeletal dysplasia, intrauterine growth retardation, chronic illness and idiopathic short stature (8-10). Moreover, a case of impaired GH secretion in $\mathrm{ACH}$ has been reported (5). It is well known that most patients with this disease suffer from hydrocephalus. This cerebral hypertension might influence the hypothalamic-pituitary axis. Furthermore, obstructive sleep apnea, which impairs sleep-related GH secretion (11), is often a complication in ACH. These features suggest that some patients with $\mathrm{ACH}$ might have hypothalamic-pituitary dysfunction, including abnormal GH secretion, subsequently contributing to short stature.

In this study we evaluated the hypothalamicpituitary function of patients with $\mathrm{ACH}$ and examined the effectiveness of $\mathrm{GH}$ administration in $\mathrm{ACH}$ diagnosed by mutation analysis (1). 


\section{Subjects and methods}

Forty-two children (16 males and 26 females), with typical or mild features of $\mathrm{ACH}$, and whose ages ranged from 3 to 14 years participated in this study at Okayama University Hospital. The diagnosis of ACH was established on the basis of clinical features, such as rhizomelic short stature, large head with a prominent forehead, lumbar lordosis and trident hand, and radiological findings, such as a large skull with a relatively small base, decreased lumbosacral interpedicular distance, a short pelvis with broad iliac wings, and short long-bones with wide and flaring metaphyses (12). The typical form was distinguished from the mild form by a markedly large head, depressed nasal bridge, trident hand and marked lumbar lordosis clinically, and narrow sacrosciatic notches, decreased vertebral interpedicular distance from L-1 to L-5 and a V-shaped appearance of the long-bone metaphyses on radiography. Thirty-five patients were prepubertal and seven were pubertal before GH therapy. Two patients had a family history of ACH. None had a history of significant neurological dysfunction. None had received any pharmacological treatment to accelerate height gain before entry into this study.

The protocol was approved by our Institutional Committee for the Protection of Human Subjects. Written informed consent was obtained from the patients and/or their parents.

\section{Hypothalamic-pituitary function before GH therapy}

GH response to provocation tests (insulin-induced hypoglycemia $(0.1 \mathrm{IU} / \mathrm{kg})$, L-dopa $(10 \mathrm{mg} / \mathrm{kg})$, clonidine $\left(0.1 \mathrm{mg} / \mathrm{m}^{2}\right)$, and GH releasing factor (GRF) $(1 \mathrm{mg} /$ $\mathrm{kg})$ ) and GH secretory pattern during sleep (assessed by averaging ten $\mathrm{GH}$ levels obtained at 20-min intervals after sleep induction) were evaluated. Serum GH concentrations were determined by an immunoradiometric assay (Daiichi Radioisotope Co., Tokyo, Japan). Luteinizing hormone (LH) and follicle-stimulating hormone (FSH) response to luteinizing hormonereleasing hormone (LHRH) stimuli and thyrotropin (TSH) response to thyrotropin-releasing hormone (TRH) stimuli were also evaluated (Dainabot, Tokyo, Japan). Intra-assay variation was less than $2.5 \%$ and interassay variation was less than $4.8 \%$ for $\mathrm{GH}$ assay. The intraassay variations of LH and FSH were less than 4.2 and $3.3 \%$ respectively, and the interassay variations were less than 6.1 and $6.2 \%$ respectively.

Less than $10 \mathrm{ng} / \mathrm{ml}$ of peak GH levels on GH provocation tests with insulin, L-dopa and clonidine, less than $15 \mathrm{ng} / \mathrm{ml}$ of peak GH levels to GH provocation test with GRF, and less than $5 \mathrm{ng} / \mathrm{ml}$ of average GH level during sleep were defined as blunted GH secretion, according to the criteria of the Foundation for Growth and Science in Japan.

\section{Analysis of genomic DNA by restriction digest}

As described in a previous report (1), genomic DNA, extracted from peripheral lymphocytes by a Blood Amp Kit (Qiagen, Chatsworth, CA, USA), was amplified using the same PCR primer set $(1,13)$. Each PCR product (10 $\mu$ l) was incubated with 4-20 U SfcI, Nla III (Biolabs, Beverly, MA, USA) or MspI (TOYOBO, Osaka, Japan) at $37^{\circ} \mathrm{C}$ from $6 \mathrm{~h}$ to overnight. The products were electrophoresed on non-denaturing $4 \%$ agarose gels and stained by ethidium bromide.

\section{GH treatment}

After evaluation of hypothalamic-pituitary function, all 42 patients were treated with recombinant human $\mathrm{GH}$ which was supplied by Novo Nordisk Pharma Ltd (Tokyo, Japan). GH was administered subcutaneously at a dose of $0.5 \mathrm{IU} / \mathrm{kg}$ per week (8 patients) or $1.0 \mathrm{IU} / \mathrm{kg}$ per week (34 patients), 6 or 7 days per week for at least 2 years. Eight patients were assigned to receive $0.5 \mathrm{IU} /$ $\mathrm{kg}$ per week treatment because they met the criteria for the GH treatment as having a GH deficiency according to the Foundation for Growth and Science in Japan.

The children were treated for more than 1 year (all patients for 1 year, 36 patients for 2 years, and 16 patients for 3 years) to determine post-treatment growth velocity and the ratio of arm span to height and of lower limb length (as assessed by the distance between spina iliaca anterior superior and internal malleolus) to height.

Blood count, urinalysis, routine laboratory tests, TSH, thyroxine $\left(\mathrm{T}_{4}\right)$, tri-iodothyronine $\left(\mathrm{T}_{3}\right)$, and serum insulin-like growth factor-I (IGF-I) were determined before and every third month during GH treatment. Serum IGF-I was measured by RIA (Ciba Corning Diagnostica, Tokyo, Japan).

Spinal canal stenosis and the foramen magnum diameter were evaluated by plain X-ray, computed tomography, or magnetic resonance imaging taken before therapy and then yearly during therapy.

Bone age was not determined because ACH may have altered the radiographic parameter used to assign bone age (6).

Data in text and tables are expressed as mean \pm S.D. Significance of differences between mean values was determined using Wilcoxon signed-ranks test, ANOVA, and Scheffe procedure for multiple comparison. $P<0.05$ was considered significant.

\section{Results}

\section{Hypothalamic-pituitary function before GH therapy}

All patients showed a normal TSH response to TRH stimulus, and cortisol response to insulin-induced hypoglycemia. Thirty-five patients showed prepubertal 


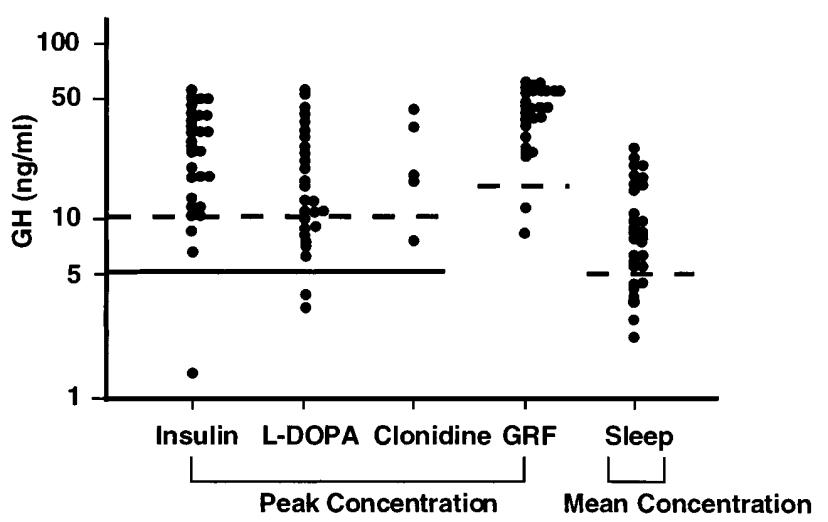

Figure $1 \mathrm{GH}$ responses to provocation tests. Peak $\mathrm{GH}$ concentrations on GH provocative tests with insulin, L-dopa, clonidine and GRF, and mean GH concentrations during sleep are shown. Dotted lines represent the cut-off value for the blunted response $(<10 \mathrm{ng} / \mathrm{ml}$ for all provocation tests other than GRF test) and the solid line

represents the cut-off value for the severe blunted response $(<5 \mathrm{ng} / \mathrm{ml})$.

LH and FSH responses to LHRH stimulus; seven patients showed pubertal responses (14). The serum $\mathrm{T}_{4}$ and $\mathrm{T}_{3}$ levels were normal in all patients.

Four patients showed blunted responses on two different provocation tests, and one showed a blunted response on three different provocation tests. Five patients showed a combination of a blunted response on one provocation test and low GH concentration during sleep (Fig. 1). As these patients showed significantly lower serum levels of IGF-I compared with age-matched normal children and $\mathrm{ACH}$ patients with normal responses to provocative tests, we suspected that 10 of the 42 patients had subnormal $\mathrm{GH}$ secretion (SGH). However no patients exhibited severe blunted responses (peak $\mathrm{GH}$ value $<5 \mathrm{ng} / \mathrm{ml}$ ) to more than one type of provocation test.

\section{Analysis of genomic DNA by restriction digest}

In the 35 typical variant forms of $\mathrm{ACH}$, we found $\mathrm{SfcI}$ polymorphism in the FGFR3 gene. In all these cases, the 55,109 and $164 \mathrm{bp}$ fragments that resulted from digestion of the PCR products with SfcI were present. However, there were neither restriction sites for SfcI nor MspI in the seven mild variant forms (1).

There was no significant difference in response to $\mathrm{GH}$ between the patient group with mutations in the transmembrane domain and those without mutations. The annual height gains in the patients with and without mutations were $6.3 \pm 0.99 \mathrm{~cm} /$ year and $7.2 \pm 1.02 \mathrm{~cm} /$ year $(P=0.439)$. In the second year of treatment, the respective gains were $4.2 \pm 0.9 \mathrm{~cm} /$ year and $5.5 \pm 1.0 \mathrm{~cm} /$ year $(P=0.105)$.

\section{GH treatment}

The mean Z-scores for height on admission and for annual height gain before admission in all the patients

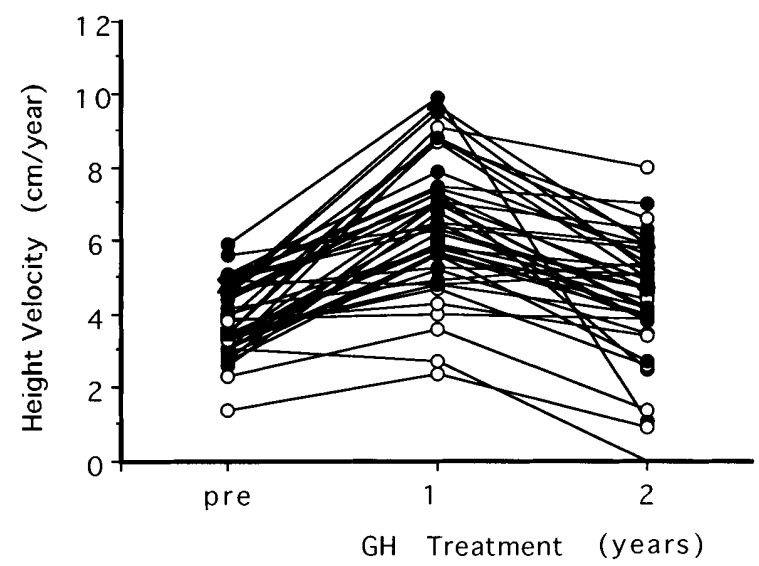

Figure 2 Individual growth profiles during $\mathrm{GH}$ treatment. (O) pubertal patients, (0) prepubertal patients.

were $-5.0 \pm 1.2$ (mean \pm S.D.) and $-3.1 \pm 1.7$ respectively. These scores are considered to be extremely low. The height velocity (HV) during the first year of GH treatment was significantly increased compared with that before therapy $(6.5 \pm 1.8 \mathrm{~cm} /$ year vs $3.9 \pm 1.0 \mathrm{~cm} /$ year, $P<0.0001)$. At the end of the second year of GH therapy $(n=36)$, although the velocity was less than that in the first year, it was still significantly greater than that before therapy $(4.6 \pm$ $1.6 \mathrm{~cm} /$ year, $P<0.002)$. In the 16 patients who received $\mathrm{GH}$ for more than 3 years, the velocity after 3 years of treatment was $5.3 \pm 1.0 \mathrm{~cm} /$ year; also lower than that in the first year but still significantly greater than before therapy $(P<0.005)$ (Figs 2 and 3$)$. It is important to notice that the responses to $\mathrm{GH}$ after the second year were not uniform. Although most patients exhibited higher velocity during GH therapy, there were some patients who showed lower HV during the second year of therapy than that before treatment.

The ratio of arm span to height was increased during GH therapy, but not to a significant degree. The ratio of

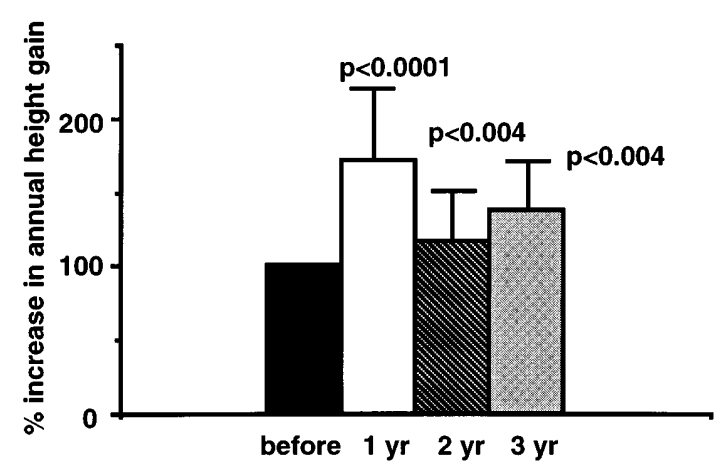

Figure 3 Annual height gain during GH therapy. This graph indicates percentage increase. $P$ values represent comparison to data before GH treatment. ANOVA and Fisher's post hoc test were used for the statistical analyses. 


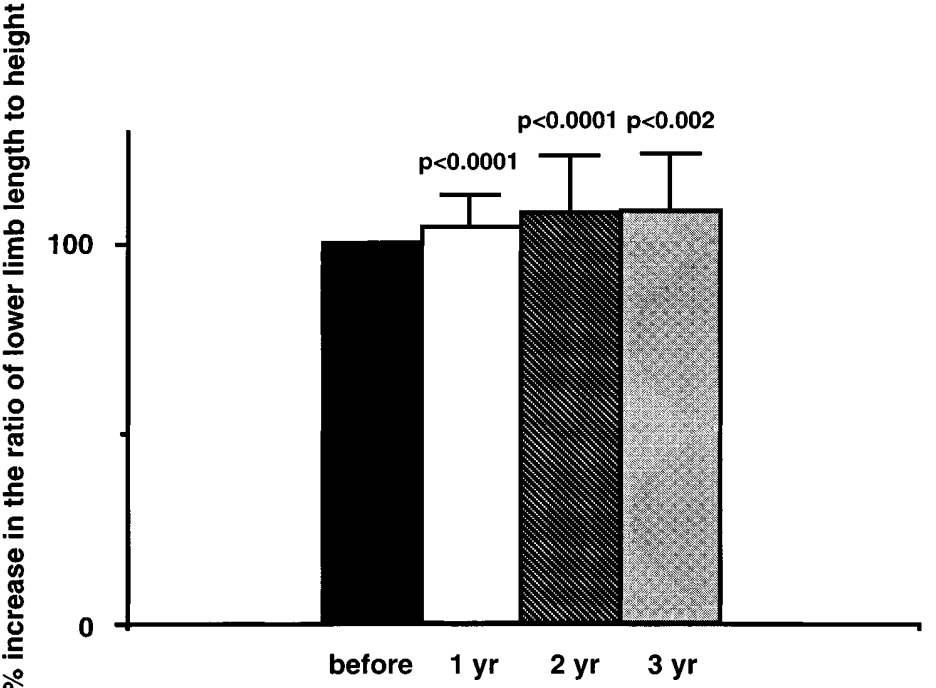

Figure 4 Ratio of lower limb length to height during GH therapy. The data indicate percentage values of the numbers before $\mathrm{GH}$ therapy. $P$ values represent comparison to the data before $\mathrm{GH}$ treatment. Error bars indicate S.D. ANOVA and Fisher's post hoc test were used for the statistical analyses.

lower limb length to height was significantly increased during treatment (Fig. 4). However, the ratio of sitting height to overall height did not show significant change during this study period (Fig. 5).

In 33 patients who did not exhibit secondary sex characteristics during the 3-year course of GH therapy, there was no significant difference in mean $\mathrm{HV}$ at the end of each year between the patients with normal $(n=23)$ or subnormal GH secretion $(n=10)$, nor was there any difference between patients treated with $0.5 \mathrm{IU} / \mathrm{kg}$ per week $\mathrm{GH}(n=8)$ and those treated with $1.0 \mathrm{IU} / \mathrm{kg}$ per week $\mathrm{GH}(n=26)$ (Table 1$)$.

Nine patients with normal $\mathrm{GH}$ secretion who exhibited secondary sex characteristics before or during the 2-year course of GH therapy, received $\mathrm{GH}$ at a dose of $1.0 \mathrm{IU} / \mathrm{kg}$ per week. The HV of these pubertal patients was significantly lower than that of the 19 prepubertal patients with normal GH secretion who were treated with $1.0 \mathrm{IU} / \mathrm{kg}$ per week $\mathrm{GH}$ after 1 year of $\mathrm{GH}$ therapy. However, there was no significant

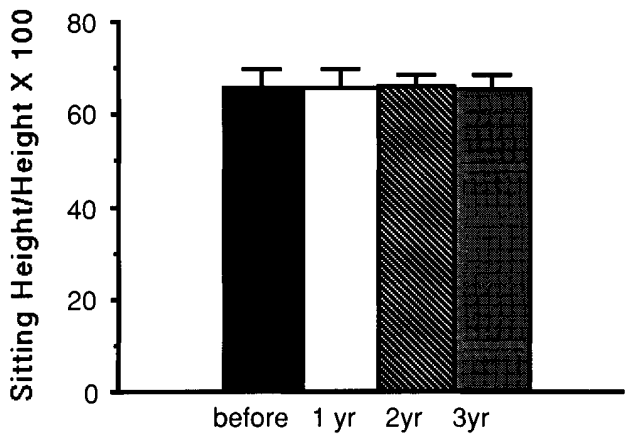

Figure 5 Ratio of sitting height to height during GH therapy. The values remain constant during the treatment. Error bars indicate S.D. ANOVA and Fisher's post hoc test were used for the statistical analyses. difference between the two groups at the end of the second year (Table 2).

The serum IGF-I level increased significantly after GH therapy $(359 \pm 196 \mathrm{ng} / \mathrm{ml}$ first year, $P<0.0001$, and $383 \pm 223$ second year, $P<0.0001$, vs $191 \pm 173$ before treatment). There were no significant changes in thyroid function tests or routine laboratory data during the GH treatment. Nor was there any noticeable change in spinal cord compression or narrowing of the foramen magnum. No adverse effects were observed during the treatment period.

\section{Hypothalamic-pituitary function after GH therapy}

Thirty-six patients who received GH treatment for more than 2 years showed normal TSH response to TRH stimulus and a normal cortisol response to insulininduced hypoglycemia at the end of the second year of therapy. Two of the 31 patients who had showed prepubertal LH and FSH responses to LHRH stimulus before GH therapy demonstrated pubertal responses after 2 years of therapy. These patients were a 10-yearold male whose testicular volume was $3 \mathrm{ml}$ and a female whose breast development was Tanner stage 2 (15).

\section{Discussion}

As observed by Shiang et al. (1) and Rousseau et al. (2), the vast majority of studies, including this and other examinations of Japanese ACH patients, have revealed $\mathrm{SfcI}$ sites, with MspI sites observed in the remainder. No patients were identified with Nla III site mutation, in this study. Further, in the mild form, we could find neither SfcI nor MspI sites, and we should therefore classify these mild forms as $\mathrm{HCH}$, as proposed by Rousseau et al. (2). There was no demonstrable 
Table 1 Mean height velocity ( \pm S.D.) in prepubertal achondroplasia patients during GH therapy.

\begin{tabular}{lcccccc}
\hline GH secretion & Group & $\begin{array}{c}\text { GH dosage } \\
\text { (IU/kg per week) }\end{array}$ & Number & $\begin{array}{c}\text { Before } \\
\text { (cm/year) }\end{array}$ & $\begin{array}{c}\text { Year 1 } \\
\text { (cm/year) }\end{array}$ & $\begin{array}{c}\text { Year 2 } \\
(\mathrm{cm} / \text { year) }\end{array}$ \\
\hline Normal & A & 1.0 & 20 & $4.1 \pm 1.0$ & $7.4 \pm 1.5$ & $4.5 \pm 1.3$ \\
Subnormal & B & 0.5 & 3 & $4.3 \pm 0.9$ & $6.8 \pm 0.5$ & $6.0 \pm 2.3$ \\
& C & 1.0 & 5 & $3.9 \pm 0.8$ & $6.8 \pm 1.6$ & $6.0 \pm 0.9$ \\
& D & 0.5 & 5 & $3.7 \pm 0.8$ & $5.9 \pm 0.7$ & $4.5 \pm 0.6$ \\
\hline
\end{tabular}

Statistical analyses were performed by Wilcoxon signed-ranks test, but there were no significant differences between groups A and B, A and $\mathrm{C}, \mathrm{C}$ and $\mathrm{D}$, and $\mathrm{B}$ and $\mathrm{D}$.

significant difference in the response to the $\mathrm{GH}$ treatment of patients with $\mathrm{ACH}$ or $\mathrm{HCH}$. This result may probably be due to the small number of patients with $\mathrm{HCH}$.

$\mathrm{GH}$ administration increased HV in a large number of ACH patients with no adverse effects. However, many of the authors of the Committee on Genetics (16) so far conclude that GH cannot be considered to be effective in increasing stature without description of data. There are several reports on GH therapy in $\mathrm{ACH}$ or $\mathrm{HCH}$ (5-7, $17,18)$, although most involved either only small numbers of patients or short-term observation. An initial growth acceleration and waning thereafter was observed in almost all cases published so far. In our study also, $\mathrm{HV}$ accelerated during the first year of $\mathrm{GH}$ treatment, but declined during subsequent years. Nevertheless, the HV during the second and third year of GH treatment was still greater than that before therapy in the majority of patients. As shown in Fig. 2 , however, there were a few patients who showed reduced growth in the second year as compared with the pretreatment period. The precise mechanisms of this low responsiveness are still unclear, although genotype difference might offer a clue. Although we could not prove a significant difference between the patients with recognizable $\mathrm{ACH}$ mutations and those without them, some $\mathrm{HCH}$ patients have been reported to respond well to $\mathrm{GH}$ therapy (19) and it may be that $\mathrm{HCH}$ is not a single entity of disorder (20). This point should be clarified by determining all the types of mutation which lead to $\mathrm{HCH}$.

The HV during the first year of $\mathrm{GH}$ treatment of patients treated with $\mathrm{GH}$ at $0.5 \mathrm{IU} / \mathrm{kg}$ per week did

Table 2 Mean height velocity ( \pm S.D.) in prepubertal and pubertal achondroplasia patients treated with $1 \mathrm{IU} / \mathrm{kg}$ per week $\mathrm{GH}$ during therapy.

\begin{tabular}{lcccc}
\hline & Number & $\begin{array}{c}\text { Before } \\
(\mathrm{cm} / \text { year })\end{array}$ & $\begin{array}{c}\text { Year 1 } \\
(\mathrm{cm} / \text { year })\end{array}$ & $\begin{array}{c}\text { Year 2 } \\
(\mathrm{cm} / \text { year })\end{array}$ \\
\hline $\begin{array}{l}\text { Prepubertal } \\
\text { Pubertal }\end{array}$ & 19 & $4.1 \pm 1.0$ & $7.4 \pm 1.5$ & $4.5 \pm 1.3$ \\
$P$ values $^{\mathrm{a}}$ & 9 & $3.4 \pm 1.1$ & $4.7 \pm 2.1$ & $3.4 \pm 2.0$ \\
$<0.005$ & $\mathrm{NS}$ \\
\hline
\end{tabular}

${ }^{a}$ Growth promoting effects were compared between prepubertal and pubertal patients by the Wilcoxon signed-ranks test. NS = not significant. not differ from those treated at $1.0 \mathrm{IU} / \mathrm{kg}$ per week. Moreover, the HV during the first year of treatment in SGH patients did not differ from that of those with normal GH secretion. This may indicate that $\mathrm{GH}$ secretion in $\mathrm{ACH}$ or $\mathrm{HCH}$ is normal, with some patients having somewhat blunted responses. After 1 year, however, the HV of pubertal patients was significantly lower than in patients during the prepubertal stage.

Further studies are therefore essential to establish the parameters of the most effective $\mathrm{GH}$ administration regimen, such as the duration of administration, dose, timing of the start of therapy, and so on.

Another important observation was that GH did not promote further disproportion. The ratio of lower limb length to height was significantly increased after GH therapy. However, a more reliable parameter in body proportion - the ratio of sitting height to height - did not change significantly during the study period. Short limbs present problems for ACH patients both psychologically and in daily life, and it is thus very meaningful that GH did not aggravate this disproportion with the increment in annual height gain.

Membranous ossification is generally considered normal in ACH, and the inner border of the foramen magnum grows by membranous ossification (6). If $\mathrm{GH}$ promotes membranous ossification, both spinal cord compression and narrowing of the foramen magnum could theoretically be worsened. However, there was no evidence of this after GH therapy. Furthermore, there is a report that by the age of 3-4 years, the foramen magnum has essentially reached its adult size in $\mathrm{ACH}$ (21). Thus, our study suggests that GH treatment might not induce neurological complications in patients over 3-4 years and could be safe.

During the 2-year course of GH therapy, two patients developed secondary sex characteristics and showed pubertal LH and FSH responses to the LHRH stimulus. The clinical features of these patients at puberty were reasonable in consideration of their ages, and were not considered to be at all excessive. We cannot guess the extent to which puberty progressed by LH and FSH responses to the LHRH stimulus, although we can judge whether the patient is prepubertal or pubertal by those responses (14). In this study, it appeared that GH did not cause sexual maturation to progress excessively.

The use of age-, sex- and genotype-matched controls was not a practicable option in this study, and we could 
not report on the adult height of the patients. A further follow-up study is thus needed to determine the adult height, but this will probably have to wait for at least 5 years. To date, we do not have any longitudinal growth curve for Japanese ACH, and its establishment should be another future project to clarify the effectiveness of this GH treatment. The comparison of growth curves during the treatment to this natural longitudinal growth curve may offer a conventional control. A cross-over study might be another way to evaluate treatment effectiveness; in fact a limited number of patients who were not included in this study were assigned to a 3-year crossover study, consisting of 1 year of treatment followed by 1 year of resting and another 1 year of treatment. The patients during the resting period showed similar growth velocities to those in the pretreatment period and regained a high growth velocity upon commencement of the second year of treatment (T Kubo, H Tanaka \& Y Seino, unpublished observations).

In conclusion, GH therapy is beneficial in the treatment of short stature in children with $\mathrm{ACH}$ and $\mathrm{HCH}$ before surgical lengthening of the lower limbs. However it is still premature to conclude that $\mathrm{GH}$ treatment will improve adult height.

\section{Acknowledgements}

This study was supported in part by grants from the Ministry of Health Welfare and the Ministry of Education of Japan and by grants from the Research Society for Metabolic Bone Diseases.

\section{References}

1 Shiang R, Thompson LM, Zhu Y-Z, Church DM, Fielder TJ, Bocian $M$ et al. Mutations in the transmembrane domain of FGFR 3 cause the most common genetic form of dwarfism, achondroplasia. Cell 199478 335-342.

2 Rousseau F, Bonaventure J, Legeai-Mallet L, Pelet A, Rozet JM, Maroteaux $\mathrm{P}$ et al. Mutations in the gene encoding fibroblast growth factor receptor-3 in achondroplasia. Nature 1994371 252-254.

3 Horton WA, Rotter JI, Rimoin DL, Scott CI \& Hall JG. Standard growth curves for achondroplasia. Journal of Pediatrics 197893 435-438.

4 Price CT. Limb lengthening for achondroplasia: early experience. Journal of Pediatric Orthopedics 1989 9 512-515.

5 Nishi Y, Kajiyama M, Miyagawa S, Fujiwara M \& Hamamoto K. Growth hormone therapy in achondroplasia. Acta Endocrinologica $1993128394-396$.
6 Horton WA, Hecht JT, Hood OJ, Marshall RN, Moore WV \& Hollowell JG. Growth hormone therapy in achondroplasia. American Journal of Medical Genetics 199242 667-670.

7 Appan S, Laurent S, Chapman S, Hindmarsh PC \& Brook CGD. Growth and growth hormone therapy in hypochondroplasia. Acta Paediatrica Scandinavica 199079 796-803.

8 Hindmarsh PC, Bridges NA \& Brook CGD. Wider indications for treatment with biosynthetic human growth hormone in children. Clinical Endocrinology 199134 417-427.

9 Genentech Collaborative Study Group. Idiopathic short stature: results of a one-year controlled study of human growth hormone treatment. Journal of Pediatrics 1989115 713-719.

10 Chatelain P, Job JC, Blanchard J, Ducret JP, Oliver M, Sagnard L et al. Dose-dependent catch-up growth after 2 years of growth hormone treatment in intrauterine growth-retarded children. Journal of Clinical Endocrinology and Metabolism 1994 78 1454-1460.

11 Goldstein SJ, Wu RHK, Thorpy MJ, Shprintzen RJ, Marion RE \& Saenger P. Reversibility of deficient sleep entrained growth hormone secretion in a boy with achondroplasia and obstructive sleep apnea. Acta Endocrinologica 1987116 95-101.

12 Sillence D. Genetic skeletal dysplasias. In Pediatrics, edn 7, pp 359362. Ed. AM Rudolph. Norwalk: Appleton-Century-Crofts, 1982.

13 Chellaiah AT, McEwen DG, Werner S, Xu J \& Ornitz DM. Fibroblast growth factor receptor (FGFR)3. Journal of Biological Chemistry $199426911620-11627$.

14 Roth JC, Kelch RP, Kaplan SL \& Grumbach MM. FSH and LH response to luteinizing hormone-releasing factor in prepubertal and pubertal children, adult males and patients with hypogonadotropic and hypergonadotropic hypogonadism. Journal of Clinical Endocrinology and Metabolism 197235 926-930.

15 Tanner JM. Growth at Adolescence, edn 2. Oxford: Blackwell Scientific Publications, 1962.

16 Committee on Genetics. Health supervision for children with achondroplasia. Pediatrics 199595 443-451.

17 Kodama H, Okabe I \& Yanagisawa M. Therapeutic benefit of growth hormone in achondroplastic dwarfism. Acta Paediatrica Japonica 199032 323-324.

18 Okabe T, NIshikawa K, Miyamori C \& Sato T. Growth-promoting effect of human growth hormone on patients with achondroplasia. Acta Paediatrica Japonica 199133 357-362.

19 Mullis PE, Patel MS, Brickell PM, Hindmarsh PC \& Brook CGD. Growth characteristics and response to growth hormone therapy in patients with hypochondroplasia: genetic linkage of the insulin-like growth factor I gene at chromosome 12q23 to the disease in a subgroup of these patients. Clinical Endocrinology $199134265-274$.

20 Rousseau F, Bonaventure J, Legeai-Mallet L, Schmidt H, Weissenbach J, Maroteaux $\mathrm{P}$ et al. Clinical and genetic heterogeneity of hypochondroplasia. Journal of Medical Genetics 199633 749-752.

21 Hecht JT, Horton WA, Reid CS, Pyeritz RE \& Chakraborty R. Growth of the foramen magnum in achondroplasia. American Journal of Medical Genetics 198932 528-535.

Received 1 October 1997

Accepted 20 October 1997 